
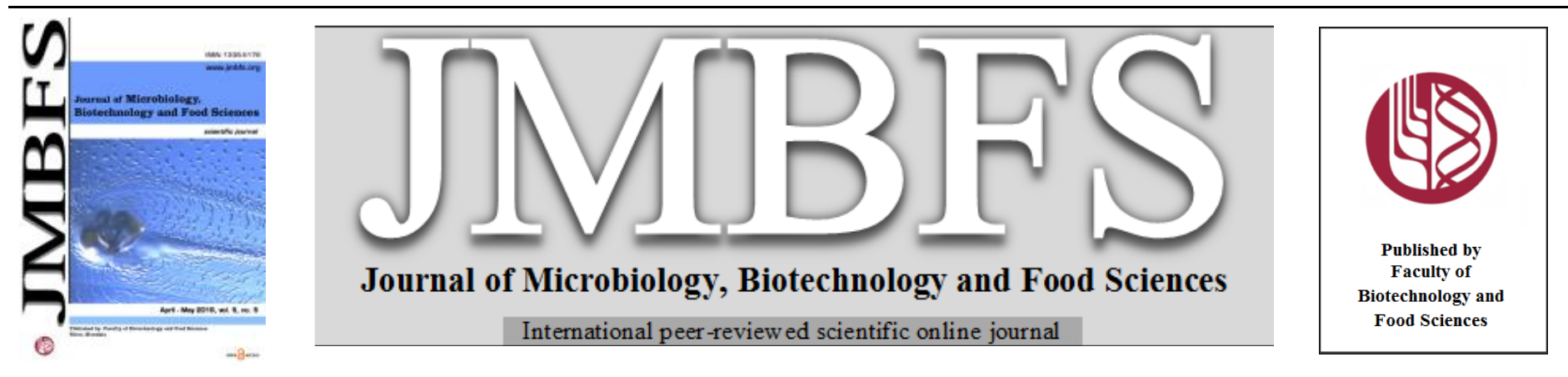

\title{
IMPACT OF FIBER MIXTURE ON DOUGH AND CHAPATTI QUALITY USING D-OPTIMAL RESPONSE SURFACE METHODOLOGY
}

\author{
Shalini S. Arya*, Sachin K. Sonawane
}

$\operatorname{Address}(e s)$ :

Food Engineering and Technology Department, Institute of Chemical Technology, Mumbai, Matunga, Mumbai - 400019, India.

*Corresponding author: shalu.ghodke@gmail.com

doi: 10.15414/jmbfs.2016.5.5.424-433

\section{ARTICLE INFO}

Received 19.8.2015

Revised 6. 1.2016

Accepted 21. 1.2016

Published 1. 4. 2016

Regular article open $\partial$ access

\begin{abstract}
Demand for health oriented products such as sugar-free, low calorie and high fiber products are increasing. One such recent trend is to increase the fiber content in food products to overcome health problems such as hypertension, diabetes, and colon cancer, among others. Chapatti is an important staple food consumed by majority of the population in the Indian subcontinent hence it can be a very good vehicle for fiber fortification. Fiber from natural sources such as wheat, soy fiber and type III resistant starch (RS) were used to study their impact on rheological characteristics of whole wheat flour dough and chapatti singly and in associated mixtures at different levels. D-optimal response surface methodology mixture design was applied to a mixture containing three ingredients: $\mathrm{x} 1$, wheat fiber, $\mathrm{x} 2$, soy fiber and $\mathrm{x} 3$, type III RS. The variation selected to each variable was based on values which were optimized on the basis of sensory properties and textural properties of chapatti, where $\mathrm{x} 1$, $\mathrm{x} 2$, $\mathrm{x} 3$ were changed from 2.5 to $5 \mathrm{~g} / 100 \mathrm{~g}$ of whole wheat flour. For each of the response variables, model summarized F-tests and lack of fit tests which were then analyzed for linear or quadratic models. Threedimensional response surface plots were generated for all quality parameter. Calculation of optimal processing conditions for optimum stickiness, strength, tear force and extensibility of dough and chapatti were performed using a multiple response method called desirability. Addition of wheat, soy fiber and type III RS in wheat flour mixture decreased dough stickiness and improved dough strength. Dough containing wheat fiber (2.5\%), soy fiber (5.0\%) and type III RS (2.5\%) yielded highly acceptable chapattis in terms of textural properties such as low tear force values and high extensibility.
\end{abstract}

Keywords: Chapatti, fiber, response surface methodology

\section{INTRODUCTION}

Cereal fiber, which have a great proportion of insoluble fiber, have physiological advantages such as the chewing mechanism, stimulation of intestine function and influence on intestine transit period (Bollinger, 2000). Health authorities, worldwide, recommend a decrease in the consumption of animal fats and proteins and an increase of cereal intake, which is an important source of dietary fiber, and, in most European countries, cereals constitute a major source of dietary fiber. In addition to these physiological properties, cereal fiber consisting mainly of cellulose have advantageous technological properties such as a high water and fat binding capacity and they are optimal ingredients for achieving high yields and reduced cost. One to three percent fiber in certain foods can also reduce lipid retention when these foods are fried (Ang, 1993; Thebaudin et al. 1997).

A wide variety of fiber from plant sources have been developed for use in various foods to provide more fiber, to improve the texture, color and aroma with a reduced energy of the final product (Jeltema et al. 1983; Morrison et al. 2008; Sánchez -Alonso et al. 2007; Yanniotis et al. 2007). Lemon and apple fiber have been reported to have relatively high water holding capacity and therefore used in cakes, breads and similar cereal products to improve the softness and the product yield with a reduced energy value of the product (Chen $\boldsymbol{e t}$ al. 1988).The development of safer and healthier low-calorie products with acceptable functional and sensory characteristics, by employing the conventional processing equipment is of major industrial concern to fulfill consumers' expectations. The latest functional significance is of major interest in the performance of lowcalorie staple foods, particularly chapatti. There are very few reports on effect of fiber addition on chapatti quality. Flour tortillas (soft tacos and tortillas, wraps, flat breads) with improved texture and nutritional characteristics were made using flour milled from specific barley cultivars with waxy starch characteristics and high levels of fiber (Ames $\boldsymbol{e t}$ al. 2003). Therefore, to meet this requirement for dietary fiber, the development of enriched chapatti with a higher dietary fiber content could be a potential option. Chapatti can be enriched with dietary fiber, including wheat bran (Ranhotra et al. 1990; Sidhu et al. 1999), soy fiber, gums, such as guar gum and modified cellulose (Pomeranz et al. 1977), $\beta$-glucans (Knuckles et al. 1997). Both the expansion and structure of these products depend on starch gelatinization, which is affected by processing conditions and raw material composition. Increasing fiber content in the form of bran resulted in premature rupture of gas cells, which reduced overall expansion of bread in one study by Mendonca et al. (2000) and Moore et al. (1990).The common experimental approach in most of the studies has been to investigate the effect of variables one at a time. However, the examination of several variables individually is laborious and time consuming. It results in large quantities of data that are difficult to interpret and, in addition, it fails to measure interaction effects. To overcome the limitations of this experimental approach, a process optimization technique that involves factorial designs and multiple regression techniques, called response surface methodology (RSM), can be used. The advantages of an RSM approach are that it examines variables simultaneously, it is less time consuming and more cost effective, and it explains any synergies between variables. Furthermore, the results may be illustrated graphically in easy to understand 2-D contour and 3-D response surface plots. When the mixture components are subject to the constraint that they must sum to one, there are standard mixture designs for fitting standard models, such as simplex-lattice designs and simplex-centroid designs. When mixture components are subject to additional constraints, such as a maximum and/or minimum value for each component, designs other than the standard mixture designs, referred to as constrained mixture designs or extreme-vertices designs, are appropriate. In mixture experiments, the measured response is assumed to depend only on the relative proportions of the ingredients or components in the mixture and not on the amount of the mixture. The amount of the mixture could also be studied as an additional factor in the experiment; however, this would be an example of mixture and process variables being treated together. Proportions of each variable must sum to 1 . The main distinction between mixture experiments and independent variable experiments is that with the former, the input variables or components are non-negative proportionate amounts of the mixture, and if expressed as fractions of the mixture, they must sum to one. If for some reason, the sum of the component proportions is less than one, the variable proportions can be rewritten as scaled fractions so that the scaled fractions sum to one. 
The purpose of the experiment in mixture design is to model the blending surfaces with some form of mathematical equation so that: predictions of the response for any mixture or combination of the ingredients can be made empirically, or some measure of the influence on the response of each component singly and in combination with other components can be obtained. The usual assumptions made for factorial experiments are also made for mixture experiments. In particular, it is assumed that the errors are independent and identically distributed with zero mean and common variance. Another assumption that is made, as with factorial designs, is that the true underlying response surface is continuous over the region being studied. D-optimal designs are often used when classical designs do not apply or work. D-optimal designs are one form of design provided by a computer algorithm. These types of computer-aided designs are particularly useful when classical designs do not apply. Unlike standard classical designs such as factorials and fractiona factorials, D-optimal design matrices are usually not orthogonal and effect estimates are correlated. These designs are always an option regardless of model or resolution desired. These types of designs are always an option regardless of the type of model the experimenter wishes to fit (for example, first order, first order plus some interactions, full quadratic, cubic, etc.) or the objective specified for the experiment (for example, screening, response surface, etc.).

Planning a mixture experiment typically involves the following steps (Cornell, 2000):

1. Define the objectives of the experiment

2. Select the mixture components and any other factors to be studied

Other factors may include process variables or the total amount of the mixture.

3. Identify any constraints on the mixture components or other factors in order to specify the experimental region.

4. Identify the response variable(s) to be measured

5. Propose an appropriate model for modeling the response data as functions of the mixture components and other factors selected for the experiment.

6. Select an experimental design that is sufficient not only to fit the proposed model, but which allows a test of model adequacy as well.

Considering all these aspects this research aims at optimizing mixtures of fiber from different sources and their effect on chapatti dough and chapatti quality fresh as well as during storage to design low-calorie chapatti formulation. The gritty texture of fiber limits their application singly. Introducing fiber in chapattis will enhance the acceptance of fiber and at the same time will improve chapattis nutritional profile. Fiber from natural sources such as wheat, soy fiber and type III resistant starch (RS) were chosen for incorporation, as rich fiber sources. Impact of fiber added singly and in associated mixtures at different levels on the chapatti dough characteristics (dough stickiness, cohesiveness, strength) and chapatti quality parameters (tear force, extensibility, color) has been evaluated by response surface methodology mixture design.

\section{MATERIALS AND METHODS}

\section{Materials}

Branded whole-wheat flour (Ashirwad atta, ITC), double filtered groundnut oil (Dhara, Amul), and table salt (Tata Co.) were procured from the local market. Very purified fiber such as wheat \& soy fiber (VITACEL ${ }^{\circledR}$ ) consisting mainly of cellulose and hemicellulose as a functional ingredient were gifted by $\mathrm{J}$ Rettenmaier \& Söhne, Rosenberg, Germany. Type III resistant starch (Hi-Maize) was gifted by National Starch and Chemical Company, Mumbai, India Preformed pouches $(15 \times 19 \mathrm{~cm})$ of four layer laminate of PET $12 \mu$, Al foil $12 \mu$, Nylon $15 \mu$, CPP $85 \mu$ was gifted by Paper Product Limited, Mumbai, India. All other chemicals used for the analysis were of analytical grade.

\section{Methods}

\section{Dough preparation and evaluation of dough stickiness}

Whole wheat flour and selected fibers at different level ranging from 5-15\% (w/w of whole wheat flour) in the form of dry formulation were mixed thoroughly and dough was prepared. Dough stickiness was measured according to the method of Hosney and Smegwish (1999).

\section{One factor at a time optimization of fibers}

In the present study the three fibers (wheat, soy and Type III RS) were optimized on the basis of one factor at a time method. Wheat, soy fiber and Type III RS were added at three different levels ranging from $5,10 \& 15 \%$ on w/w basis of whole wheat flour. The dough was prepared and effect of level of fiber added on dough stickiness, dough strength and cohesiveness was studied.

\section{Design of experiment}

Once the level of fiber was optimized D-optimal mixture design was constructed using the software Design Expert Version 6.0.10 (Stat-Ease Corporation, Minneapolis, Minn., USA) and was used to analyze the results. Maximum and minimum predictor variable levels were chosen by carrying out preliminary trials as explained above. The sum of the factors were kept constant that is at 10 .

\section{Response surface methodology D-optimal mixture design}

D-optimal mixture design applied to a mixture containing three ingredients: $\mathrm{x}_{1}$ wheat fiber, $\mathrm{x}_{2^{-}}$soy fiber and $\mathrm{x}_{3}$ - type III RS. The variation selected to each variable was based on values which were optimized on the basis of sensory properties and textural properties, where $\mathrm{x}_{1}, \mathrm{x}_{2}, \mathrm{x}_{3}$ were changed from 2.5 to 5 $\mathrm{g} / 100 \mathrm{~g}$ of wheat flour. For each of the response variables, model summaries Ftests and lack of fit tests which were then analyzed for linear or quadratic models. The cubic model was aliased because there were not enough points for this type of model. From this information, the most accurate model was chosen via the sequential F-tests, lack-of-fit tests and other adequacy measures. Threedimensional response surface plots were generated for each quality parameter. Calculation of optimal processing conditions for optimum tear force $(\mathrm{g})$ and extensibility ( $\mathrm{mm}$ ) of chapatti was performed using a multiple response method called desirability (Box and Wilson, 1951; Myers and Montgomery, 1995). This optimization method incorporates desires and priorities for each of the variables. In this study, predictor variables were permitted to be at any level within the range of the design. Statistical experimental design was used to optimize the level of fiber in a mixture to obtain flour of mixed fibers from different sources, which was checked with respect to effect on dough stickiness and tear force and extensibility of chapatti.

For statistical calculations, the relationship between the coded values and actual values are described by the following equation:

$$
X_{i}=\frac{A_{i}-A_{0}}{\Delta A}
$$

Where, $\mathrm{X}_{\mathrm{i}}$ is coded value of variable; $\mathrm{A}_{\mathrm{i}}$ the actual value of variable; $\mathrm{A}_{0}$ the actua value of the $A_{i}$ at the center point; and $\Delta A$ the step change of variable. Chapatti tear force $(\mathrm{g})$, extensibility $(\mathrm{mm})(0,1,2$ days) was taken as response variables.

Experiments were carried out in triplicate.

Quadratic equation for the variable was as follows

$$
\mathrm{Y}=\beta 0+\Sigma \beta \mathrm{i} \mathrm{Xi}+\Sigma \beta \mathrm{ii} \mathrm{Xi} \mathrm{Xj}+\Sigma \mathrm{i} \Sigma \mathrm{j} \beta \mathrm{ij} \mathrm{Xi} X \mathrm{j}
$$

$\mathrm{Y}$ is the predicted response; $\beta 0$ a constant; $\beta \mathrm{i}$ the linear coefficient; $\beta \mathrm{ii}$ the squared coefficient; and $\beta \mathrm{ij}$ the cross-product coefficient.

The above quadratic equation was used to build surfaces for the variables. The software Design Expert Version 6.0.10 was used to analyze the results. Threedimensional mixtures plots of three factors versus tear force $(\mathrm{g})$ and extensibility $(\mathrm{mm})$ were obtained.

Preparation and evaluation of chapatti for tear force and extensibility and color ( $\mathbf{L}$ a b).

In the present study chapattis were prepared and evaluated for tear force and extensibility according to the method of Ghodke et al. (2009).

\section{RESULTS AND DISCUSSION}

\section{Effect of fiber addition on dough and chappti}

Table 1 shows the effect of fiber addition on the stickiness of chapatti dough with added fiber. Wheat, soy fibers and type III RS were added into whole wheat flour at three levels viz., 5, 10 and $15 \%$ w/w of whole wheat flour. From Table 1 it can be observed that control dough showed dough stickiness of $33.36 \mathrm{~g}$ and with the addition of wheat fiber the stickiness was increased to $38.05 \mathrm{~g}$ at $5 \%$. High water absorption attributed to decrease in the water binding capacity of gluten (Dreese et al. 1982) thus increased stickiness. The effect has been attributed to the hydroxyl groups in the fiber structure, which allows more water interactions through hydrogen bonding (Guarda et al. 2004). 
Table 1- Effect of fiber addition on dough stickiness, dough strength and dough cohesiveness

\begin{tabular}{lccc}
\hline Sample & $\begin{array}{c}\text { Dough } \\
\text { stickiness }(\mathrm{g})\end{array}$ & $\begin{array}{c}\text { Dough } \\
\text { strength }(\mathrm{g})\end{array}$ & $\begin{array}{c}\text { Dough } \\
\text { cohesiveness }(\mathrm{mm} / \mathrm{s})\end{array}$ \\
\hline Control & $33.36 \pm 1.77$ & $1.66 \pm 0.30$ & $1.79 \pm 0.34$ \\
$5 \mathrm{~g} \mathrm{WF}$ & $38.05 \pm 3.32$ & $2.82 \pm 0.88$ & $2.07 \pm 0.59$ \\
$10 \mathrm{~g} \mathrm{WF}$ & $36.64 \pm 4.43$ & $2.42 \pm 0.92$ & $1.94 \pm 0.48$ \\
$15 \mathrm{~g} \mathrm{WF}$ & $32.19 \pm 2.41$ & $2.79 \pm 0.46$ & $1.88 \pm 0.46$ \\
$5 \mathrm{~g}$ SF & $31.52 \pm 2.82$ & $2.04 \pm 0.44$ & $1.34 \pm 0.31$ \\
$10 \mathrm{~g}$ SF & $29.05 \pm 1.87$ & $1.65 \pm 0.29$ & $1.14 \pm 0.39$ \\
$15 \mathrm{~g}$ SF & $29.85 \pm 2.71$ & $1.35 \pm 0.28$ & $0.81 \pm 0.28$ \\
$5 \mathrm{~g}$ Type III RS & $38.26 \pm 2.70$ & $2.04 \pm 0.58$ & $1.81 \pm 0.16$ \\
$10 \mathrm{~g}$ Type III RS & $35.82 \pm 3.35$ & $1.84 \pm 0.41$ & $1.64 \pm 0.72$ \\
$15 \mathrm{~g}$ Type III RS & $34.66 \pm 2.17$ & $1.47 \pm 0.14$ & $1.58 \pm 0.34$ \\
\hline All the values are mean \pm sd 0 three values; wf: wheat fiber; sf: soy fiber
\end{tabular}

Further addition of $10 \%$ and $15 \%$ wheat fiber, the dough stickiness was decreased due to the dilution of the gluten, as gluten fractions, have been shown to be important determinants of dough stickiness. Dough stickiness was reduced by addition of flour protein fractions concentrated in glutenin proteins (Dhaliwal and Mac Ritchie, 1990); gliadins have also been reported as responsible for dough adhesiveness (Ram and Nigam, 1983). When soy fiber was added the dough stickiness was decreased, this was due to the less water absorption of the soy fiber. These results could be explained by the interactions between fibers and gluten, as suggested by Chen $\boldsymbol{e t}$ al. (1988). With the addition of type III RS, dough stickiness was increased at 5\% level but it decreased with increased level Water absorption is generally accepted to be of main importance in dough stickiness (Noguchi et al. 1976; Gaines, 1982; Dhaliwal et al. 1990; Heddleson et al. 1994). The higher the water absorption, the more sticky dough it gives (Hlynka, 1970; Chen and Hoseney, 1995; Armero and Collar, 1997). Adding excess water to flour produces dough with better wetting properties. The dough surface is in better contact with the surface of a probe, giving higher surface adhesion. The dough strength observed in wheat fiber added dough was higher than the control, and in case of soy fiber the dough strength was decreased with the increased level of soy fiber, type III RS at $5 \%$ concentration resulted in small increase in dough strength but decreased with the increased concentration. Similar results were obtained by Sudha et al. (2007) who observed the weakening of the dough with the increased level of the fibers.

Table 2 Effect of fiber addition on chapatti tear force $(\mathrm{g})$ and extensibility $(\mathrm{mm})$ over a period of 2 days storage at $37 \pm 2{ }^{\circ} \mathrm{C}$

\begin{tabular}{|c|c|c|c|c|c|c|}
\hline \multirow[b]{2}{*}{ Sample } & \multicolumn{2}{|c|}{0 Day } & \multicolumn{2}{|c|}{1 Day } & \multicolumn{2}{|c|}{2 Day } \\
\hline & Tear force $(\mathrm{g})$ & Extensibility (mm) & Tear force $(\mathrm{g})$ & $\begin{array}{c}\text { Extensibility } \\
(\mathrm{mm})\end{array}$ & Tear force $(\mathrm{g})$ & Extensibility $(\mathrm{mm})$ \\
\hline Control & $316.45 \pm 35.46$ & $5.51 \pm 0.59$ & $358.61 \pm 23.47$ & $1.66 \pm 0.38$ & $447.64 \pm 83.38$ & $1.22 \pm 0.14$ \\
\hline $5 \mathrm{~g} \mathrm{WF}$ & $283.74 \pm 40.34$ & $3.90 \pm 0.49$ & $427.96 \pm 106.43$ & $2.74 \pm 0.96$ & $363.55 \pm 40.78$ & $1.52 \pm 0.27$ \\
\hline $10 \mathrm{~g} \mathrm{WF}$ & $261.18 \pm 85.63$ & $3.68 \pm 1.27$ & $365.24 \pm 43.50$ & $1.86 \pm 0.34$ & $356.04 \pm 16.67$ & $1.50 \pm 0.10$ \\
\hline $15 \mathrm{~g} \mathrm{WF}$ & $260.79 \pm 44.28$ & $3.22 \pm 0.70$ & $322.28 \pm 92.03$ & $1.88 \pm 0.24$ & $350.63 \pm 45.78$ & $1.98 \pm 0.17$ \\
\hline $5 \mathrm{~g} \mathrm{SF}$ & $238.09 \pm 28.11$ & $4.82 \pm 0.92$ & $374.59 \pm 43.17$ & $1.93 \pm 0.15$ & $445.33 \pm 125.52$ & $1.55 \pm 0.33$ \\
\hline $10 \mathrm{~g} \mathrm{SF}$ & $232.38 \pm 19.11$ & $4.75 \pm 0.62$ & $358.76 \pm 45.86$ & $1.88 \pm 0.61$ & $438.91 \pm 56.20$ & $1.54 \pm 0.17$ \\
\hline $15 \mathrm{~g} \mathrm{SF}$ & $213.52 \pm 30.60$ & $3.66 \pm 0.38$ & $330.79 \pm 67.63$ & $1.81 \pm 0.22$ & $413.47 \pm 56.40$ & $1.23 \pm 0.26$ \\
\hline 5 Type III RS & $345.24 \pm 60.60$ & $5.06 \pm 1.22$ & $503.02 \pm 98.82$ & $2.05 \pm 0.44$ & $492.86 \pm 20.21$ & $1.49 \pm 0.19$ \\
\hline 10 Type III RS & $335.45 \pm 67.74$ & $4.91 \pm 1.44$ & $590.15 \pm 72.20$ & $1.45 \pm 0.19$ & $492.00 \pm 64.57$ & $2.62 \pm 2.95$ \\
\hline 15 Type III RS & $334.93 \pm 56.31$ & $4.16 \pm 0.89$ & $661.17 \pm 2.72$ & $1.61 \pm 0.33$ & $438.38 \pm 27.21$ & $1.31 \pm 0.28$ \\
\hline
\end{tabular}

Cohesiveness may be measured as the rate at which the material disintegrates under mechanical action. From Table .1 it can be seen that the cohesiveness of the dough samples were decreased with the increased level of fibers. This may likely be due to the interaction between polysaccharides and proteins from wheat flour as reported earlier by Jones and Erlander (1967). The reduction in dough cohesiveness values due to various cereal fibers addition have been reported by (Sudha et al. 2007; Piteira et al. 2006). The increase in dietary fiber content has been reported to cause several changes in wheat dough and bread: dough yield increases by $3-5 \%$, the dough becomes shorter and moister and fermentation tolerance decreases (Seibel, 1983). Other dough properties e.g. kneading, handling properties, rising, fermentation, post-stiffening and stickiness can also be affected. The proportion of soluble and insoluble fiber influences the water absorption rate of the flour mixture (Haseborg and Himmelstein, 1988).

All the values are mean \pm sd of three values; wf: wheat fiber; sf: soy fiber

Table 2 shows the effect of fiber addition on the chapatti tear force and extensibility. Tear force which indicates the force required to tear the chapatti. Decrease in tear force indicates the increase in softness of the chapatti whereas increase in tear force indicates the increase in hardness of chapatti. From Table 2 it can be observed that the softness was increased with the increased level of wheat fiber. Control chapatti showed $316.45 \mathrm{~g}$ tear force whereas with the addition of wheat fiber the softness of chapatti was increased; when soy fiber was added, softness was further increased. This might be due to the method of manufacturing for these two fibers is different and the difference in the composition of two, as the soy fiber manufacturing involves addition of small quantity of soy lecithin, and this lecithin which acts as an emulsifier thus acted as softening and natural antistaling agent (Ranhotra, 1993) in chapatti. Further, with the addition of type III RS chapatti hardness was increased; this was due to the high amylose content of the type III RS (www.hi-maize.com). Studies have shown that granular resistant starch provides better appearance, texture, and mouth feel than do conventional fiber sources and improves expansion and crispness in certain food applications (Waring, 1998). In a study conducted at the American Institute of Baking, NOVELOSE 240 starch was compared to various traditional fibers in a high- fiber sponge and dough formulation. Breads were supplemented with fiber or resistant starch to obtain a "high source" of fiber (5 $\mathrm{g} / 50 \mathrm{~g}$ serving or $10 \% \mathrm{TDF}$ ). A blend in which resistant starch and oat fiber each contributed to half of the desired TDF was included to demonstrate how resistant starch can complement other fiber sources. Breads containing resistant starch were determined to have superior quality compared to those made with traditional fibers (Waring, 1998). Extensibility which indicates the chapatt elasticity, high extensibility values indicate fresh chapatti and with storage due to staling and retrogradation chapatti loses its extensibility (Shaikh et al. 2007) hence lower extensibility values indicates staled chapatti (Shaikh et al. 2008) From Table 2 it can be observed that with the fiber addition, extensibility of the chapatti was decreased due to the dilution of the gluten protein, whereas with the addition of type III RS; chapatti was found more extensible as can be seen from extensibility values. During two days storage of chapatti soy fiber shown to have an antistaling effect as can be seen from the lower tear force and high extension values as compared to control chapatti. Similar type of results were reported by Seibel (1983) who observed marked changes in loaf properties such as decreased bread volume and its elasticity. In another study by Abdul-Hamid and Siew Luan (2000), addition of defatted rice bran as a source of dietary fiber in bread making resulted into reduced loaf volume and increased firmness of the bread.

Effect of fiber mixtures on dough stickiness, chapatti tear force and extensibility 
Table 3- Experimental D-Optimal mixture design and responses for dough stickiness, strength \& cohesiveness obtained from fiber mixture

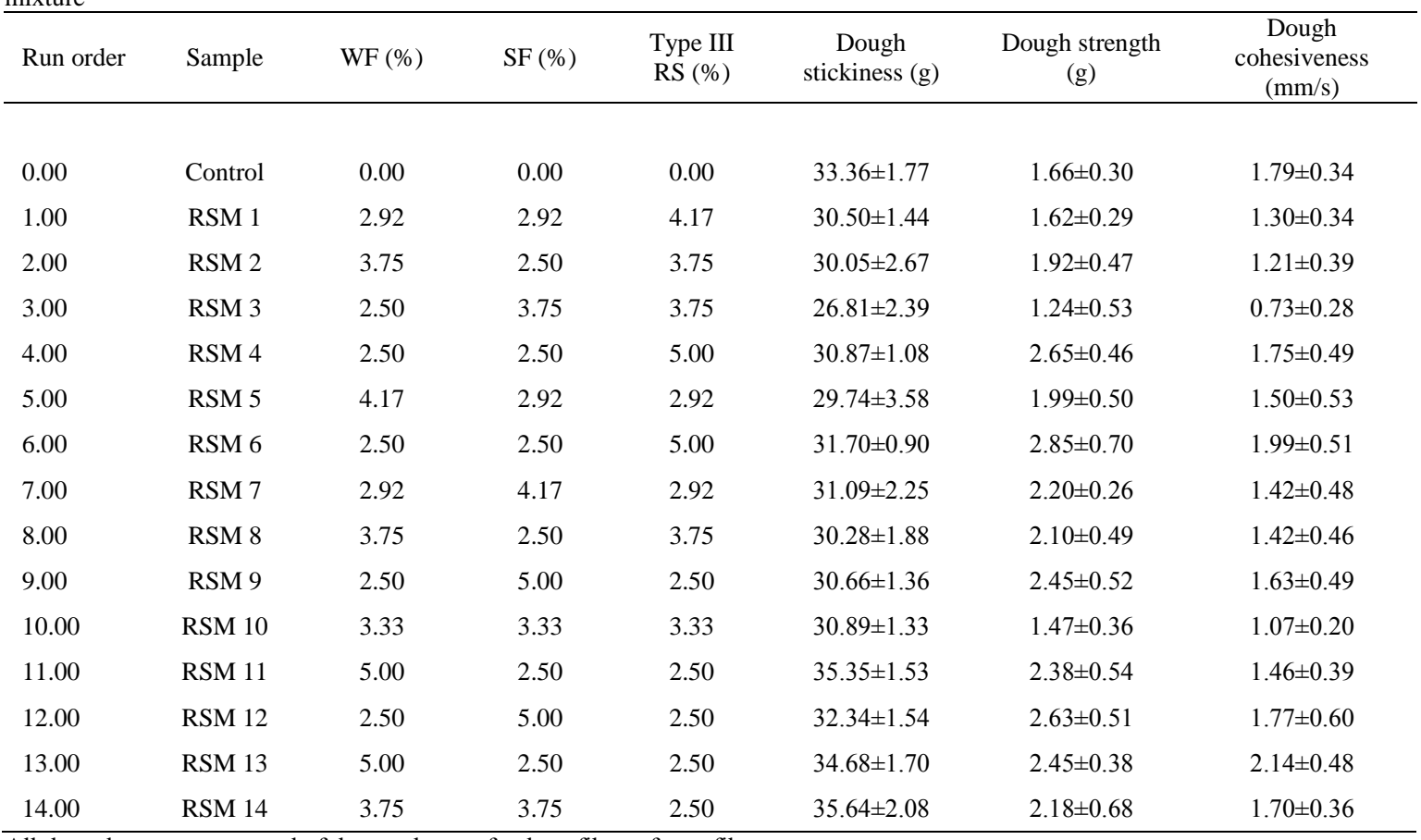

All the values are mean \pm sd of three values; wf: wheat fiber; sf: soy fiber

Table 3 shows the levels of selected predictor variables for the D-optimal mixture design and summarizes the experimental design for optimization of fiber mixtures. To examine the combined effect of three different components (independent variables) on dough stickiness, dough strength and dough cohesiveness, D-optimal mixture design of 1-14 experiments were performed with different combinations (Table 3). Table 4 also includes data showing effect of fiber mixture on chapatti tear force and extensibility (0, 1, 2 days) as a response. The application of RSM yielded following regression equation, which is an empirical relation between tear force 0 day $\left(\mathrm{X}_{1}\right)$, tear force 1 day $\left(\mathrm{X}_{2}\right)$, tear force 2 day $\left(\mathrm{X}_{3}\right)$ and the test variable (A- wheat fiber, B- soy fiber, C- type III $\mathrm{RS})$ in coded units.
$\mathrm{X}_{1}$ : Tear force $(0 \mathrm{D})=+338.69 * \mathrm{~A}+256.19 * \mathrm{~B}+348.32 * \mathrm{C}-128.41 * \mathrm{~A} * \mathrm{~B}$ $178.31 * \mathrm{~A} * \mathrm{C}-6.75 * \mathrm{~B} * \mathrm{C}$

$\mathrm{X}_{2}$ : Tear force $(1 \mathrm{D})=+474.28 * \mathrm{~A}+328.60 * \mathrm{~B}+528.65 * \mathrm{C}-265.01 * \mathrm{~A}^{*} \mathrm{~B}$ $525.46 * \mathrm{~A} * \mathrm{C}-249.64 * \mathrm{~B} * \mathrm{C}$

$\mathrm{X}_{3}$ : Tear force $(2 \mathrm{D})=+496.40 * \mathrm{~A}+380.93 * \mathrm{~B}+554.75 * \mathrm{C}-95.01 * \mathrm{~A}^{*} \mathrm{~B}$ $316.85 * \mathrm{~A} * \mathrm{C}-52.40 * \mathrm{~B} * \mathrm{C}$

Table 4- Experimental D-Optimal mixture design and responses for tear force ( $\mathrm{g})$, extensibility ( $\mathrm{mm})$ of chapatti $(0,1 \& 2$ day) prepared with fiber mixture addition

\begin{tabular}{|c|c|c|c|c|c|c|c|c|c|}
\hline \multicolumn{4}{|c|}{ D-Optimal Mixture Design } & \multicolumn{2}{|c|}{0 Day } & \multicolumn{2}{|c|}{1 Day } & \multicolumn{2}{|c|}{2 Day } \\
\hline $\begin{array}{l}\text { Run } \\
\text { order }\end{array}$ & $\mathrm{WF}(\%)$ & $\mathrm{SF}(\%)$ & $\begin{array}{c}\text { Type III RS } \\
(\%)\end{array}$ & Tear force $(\mathrm{g})$ & $\begin{array}{l}\text { Extensibility } \\
(\mathrm{mm})\end{array}$ & Tear force $(\mathrm{g})$ & $\begin{array}{l}\text { Extensibility } \\
(\mathrm{mm})\end{array}$ & Tear force $(\mathrm{g})$ & $\begin{array}{c}\text { Extensibili } \\
\text { ty }(\mathrm{mm})\end{array}$ \\
\hline 1.00 & 2.92 & 2.92 & 4.17 & $327.82 \pm 57.13$ & $3.48 \pm 0.61$ & $426.76 \pm 69.35$ & $1.62 \pm 0.42$ & $489.86 \pm 49.74$ & $1.16 \pm 0.33$ \\
\hline 2.00 & 3.75 & 2.50 & 3.75 & $293.70 \pm 58.08$ & $3.98 \pm 0.96$ & $375.23 \pm 57.91$ & $2.02 \pm 0.43$ & $439.04 \pm 39.24$ & $1.78 \pm 0.26$ \\
\hline 3.00 & 2.50 & 3.75 & 3.75 & $294.07 \pm 74.65$ & $3.85 \pm 0.73$ & $345.21 \pm 48.72$ & $1.86 \pm 1.04$ & $457.24 \pm 29.93$ & $1.45 \pm 0.30$ \\
\hline 4.00 & 2.50 & 2.50 & 5.00 & $342.87 \pm 72.73$ & $3.70 \pm 0.59$ & $527.35 \pm 72.87$ & $1.54 \pm 0.39$ & $550.01 \pm 10.15$ & $1.30 \pm 0.18$ \\
\hline 5.00 & 4.17 & 2.92 & 2.92 & $287.75 \pm 56.02$ & $3.90 \pm 0.23$ & $341.35 \pm 58.59$ & $1.86 \pm 0.09$ & $454.77 \pm 25.43$ & $1.38 \pm 0.20$ \\
\hline 6.00 & 2.50 & 2.50 & 5.00 & $348.16 \pm 87.42$ & $3.73 \pm 0.59$ & $521.96 \pm 60.29$ & $1.59 \pm 0.29$ & $554.30 \pm 31.88$ & $1.34 \pm 0.23$ \\
\hline 7.00 & 2.92 & 4.17 & 2.92 & $261.81 \pm 58.10$ & $4.22 \pm 0.93$ & $326.68 \pm 97.82$ & $2.03 \pm 0.36$ & $376.23 \pm 47.01$ & $1.80 \pm 0.34$ \\
\hline 8.00 & 3.75 & 2.50 & 3.75 & $297.83 \pm 60.05$ & $3.94 \pm 0.75$ & $355.69 \pm 35.14$ & $1.98 \pm 0.47$ & $441.90 \pm 59.88$ & $1.66 \pm 0.33$ \\
\hline 9.00 & 2.50 & 5.00 & 2.50 & $258.17 \pm 97.28$ & $4.49 \pm 0.75$ & $329.10 \pm 57.65$ & $2.09 \pm 0.21$ & $389.93 \pm 18.97$ & $1.93 \pm 0.40$ \\
\hline 10.00 & 3.33 & 3.33 & 3.33 & $278.26 \pm 50.33$ & $3.80 \pm 1.19$ & $335.04 \pm 3.69$ & $1.70 \pm 0.25$ & $426.65 \pm 6.26$ & $1.49 \pm 0.07$ \\
\hline 11.00 & 5.00 & 2.50 & 2.50 & $340.57 \pm 45.30$ & $4.38 \pm 0.65$ & $481.08 \pm 45.59$ & $2.08 \pm 0.52$ & $489.14 \pm 46.14$ & $1.65 \pm 0.21$ \\
\hline 12.00 & 2.50 & 5.00 & 2.50 & $256.64 \pm 39.17$ & $4.57 \pm 0.89$ & $327.36 \pm 51.76$ & $2.14 \pm 0.35$ & $381.82 \pm 7.48$ & $1.92 \pm 0.31$ \\
\hline 13.00 & 5.00 & 2.50 & 2.50 & $339.56 \pm 58.44$ & $4.37 \pm 1.03$ & $478.46 \pm 44.24$ & $2.04 \pm 0.06$ & $499.26 \pm 64.19$ & $1.68 \pm 0.33$ \\
\hline 14.00 & 3.75 & 3.75 & 2.50 & $267.21 \pm 66.35$ & $4.10 \pm 0.83$ & $333.16 \pm 2.44$ & $1.72 \pm 0.21$ & $418.20 \pm 66.18$ & $1.57 \pm 0.42$ \\
\hline
\end{tabular}

All the values are mean \pm sd of three values; wf: wheat fiber; sf: soy fiber

The results of the second order response surface model fitting in the form of ANOVA for chapatti tear force ( $\mathrm{g}$ ) obtained by mixture design quadratic model is given in Table 5. The ANOVA of quadratic regression model demonstrates that the model is significant, as is evident from Fisher's F- test value being 40.57, $44.72 \& 41.09$ for tear force ( 0 day), tear force ( 1 day) and tear force ( 2 day) respectively, with a very low probability value for tear force $0,1 \& 2$ days $[(\mathrm{P}$ model $>\mathrm{F})=0.0001]$. The goodness of the fit of the model was checked by regression coefficient $\left(\mathrm{R}^{2}\right)$. In this case, the value of regression coefficient for tear force 0,1 and 2 days was $R^{2}=0.9621,0.9655 \& 0.9625$ respectively. The $R^{2}$ value is always between 0 and 1 and the closer the $R^{2}$ is to 1.0 , the stronger the model and the better it predicted the response (Haaland, 1989). For the tear force (0 day) response, mutual interaction of wheat fiber \& type III RS (AC) ( $\mathrm{P}<$ 
0.0002) has the largest effect on tear force followed by wheat and soy fiber (AB) $\quad 0.8439)$ (Table 5).

$(\mathrm{P}<0.0048)$. Soy fiber, type III RS interaction was found to be insignificant ( $\mathrm{P}<$

Table 5 - ANOVA for chapatti tear force $(\mathrm{g})$ obtained by mixture design quadratic model

\begin{tabular}{|c|c|c|c|c|c|c|c|c|c|c|c|c|}
\hline \multirow[b]{2}{*}{ Source } & \multicolumn{4}{|c|}{ Tear force $(g)(0$ day $)$} & \multicolumn{4}{|c|}{ Tear force (g) (1 day) } & \multicolumn{4}{|c|}{ Tear force (g) (2 day) } \\
\hline & SS* & DF & $\begin{array}{c}\text { F } \\
\text { value }\end{array}$ & $\begin{array}{c}\text { Prob > } \\
\text { F }\end{array}$ & SS* & $\mathrm{DF}^{*}$ & $\begin{array}{c}F \\
\text { value }\end{array}$ & $\begin{array}{c}\text { Prob > } \\
\text { F }\end{array}$ & SS* & DF* & $\begin{array}{c}\mathbf{F} \\
\text { value }\end{array}$ & $\begin{array}{c}\text { Prob > } \\
\text { F }\end{array}$ \\
\hline Model & 14434.53 & 5 & 40.57 & $<0.0001$ & 74602.06 & 5.00 & 44.72 & $<0.0001$ & 40050.96 & 5.00 & 41.09 & $<0.0001$ \\
\hline $\begin{array}{l}\text { Linear } \\
\text { Mixture }\end{array}$ & 10418.34 & 2 & 73.21 & $<0.0001$ & 39326.33 & 2.00 & 58.94 & $<0.0001$ & 29885.96 & 2.00 & 76.66 & $<0.0001$ \\
\hline $\mathrm{AB}$ & 1064.42 & 1 & 14.96 & 0.0048 & 4533.87 & 1.00 & 13.59 & 0.0062 & 582.75 & 1.00 & 2.99 & 0.1221 \\
\hline $\mathrm{AC}$ & 2948.83 & 1 & 41.44 & 0.0002 & 25608.22 & 1.00 & 76.75 & $<0.0001$ & 9311.31 & 1.00 & 47.77 & 0.0001 \\
\hline $\mathrm{BC}$ & 2.94 & 1 & 0.04 & 0.8439 & 4023.17 & 1.00 & 12.06 & 0.0084 & 177.23 & 1.00 & 0.91 & 0.3682 \\
\hline Residual & 569.23 & 8 & & & 2669.12 & 8.00 & & & 1559.43 & 8.00 & & \\
\hline Lack of fit & 545.67 & 4 & 23.17 & 0.0050 & 2458.74 & 4.00 & 11.69 & 0.0177 & 1462.05 & 4.00 & 15.01 & 0.0112 \\
\hline $\mathrm{R}^{2}$ & 0.9621 & & & & 0.9655 & & & & 0.9625 & & & \\
\hline $\operatorname{Adj} R^{2}$ & 0.9383 & & & & 0.9439 & & & & 0.9391 & & & \\
\hline
\end{tabular}

*ss- sum of square, df- degree of freedom, A - wheat fiber, B - soy fiber, C - type iii rs

Table 6 shows ANOVA for chapatti extensibility obtained by mixture design. For the extensibility ( 0 day) response, mutual interaction of wheat fiber \& soy fiber $(\mathrm{AB})(\mathrm{P}<0.0107)$ has the largest effect on extensibility followed by soy fiber $\&$ type III RS (BC) $(\mathrm{P}<0.0219)$ and the interaction of wheat fiber and type III RS $(\mathrm{AC})(\mathrm{P}<0.1856)$ showed to be insignificant.

Table 6 - ANOVA for chapatti extensibility ( $\mathrm{mm})$ obtained by mixture design

\begin{tabular}{|c|c|c|c|c|c|c|c|c|c|c|c|c|}
\hline \multirow[b]{2}{*}{ Source } & \multicolumn{4}{|c|}{ Extensibility (mm) (0 day) } & \multicolumn{4}{|c|}{ Extensibility (mm) (1 day) } & \multicolumn{4}{|c|}{ Extensibility (mm) (2 day) } \\
\hline & $\mathbf{S S}^{*}$ & DF & F value & Prob $>$ F & SS* & $\mathbf{D F}^{*}$ & F value & Prob $>$ F & $\mathbf{S S}^{*}$ & $\mathbf{D F}^{*}$ & F value & Prob $>$ F \\
\hline Model & 1.2848 & 5 & 18.50 & 0.0003 & 0.4896 & 5 & 11.91 & 0.0015 & 0.4896 & 5 & 11.91 & 0.0015 \\
\hline Linear Mixture & 0.9597 & 2 & 34.54 & 0.0001 & 0.3017 & 2 & 18.35 & 0.0010 & 0.3017 & 2 & 18.35 & 0.0010 \\
\hline $\mathrm{AB}$ & 0.1524 & 1 & 10.97 & 0.0107 & 0.1518 & 1 & 18.47 & 0.0026 & 0.1518 & 1 & 18.47 & 0.0026 \\
\hline $\mathrm{AC}$ & 0.0291 & 1 & 2.10 & 0.1856 & 0.0322 & 1 & 3.91 & 0.0833 & 0.0322 & 1 & 3.91 & 0.0833 \\
\hline $\mathrm{BC}$ & 0.1118 & 1 & 8.05 & 0.0219 & 0.0005 & 1 & 0.06 & 0.8116 & 0.0005 & 1 & 0.06 & 0.8116 \\
\hline Residual & 0.1111 & 8 & & & 0.0658 & 8 & & & 0.0658 & 8 & & \\
\hline Lack of fit & 0.1066 & 4 & 23.69 & 0.0048 & 0.0617 & 4 & 15.04 & 0.0112 & 0.0617 & 4 & 15.04 & 0.0112 \\
\hline $\mathrm{R}^{2}$ & 0.9204 & & & & 0.8816 & & & & 0.8816 & & & \\
\hline Adj R-Squared & 0.8706 & & & & 0.8075 & & & & 0.8075 & & & \\
\hline
\end{tabular}

*ss- sum of square, DF- degree of freedom, A - wheat fiber, B - soy fiber, C - type III RS 


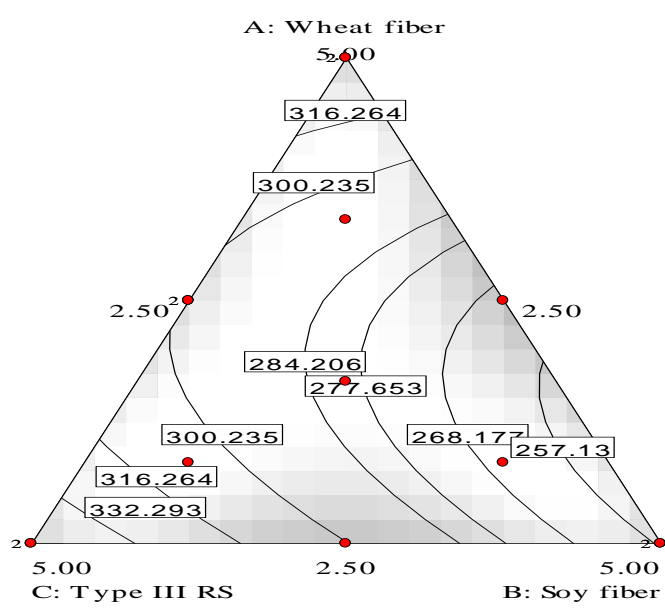

Tear force (O D)

Fig. 1 (a)

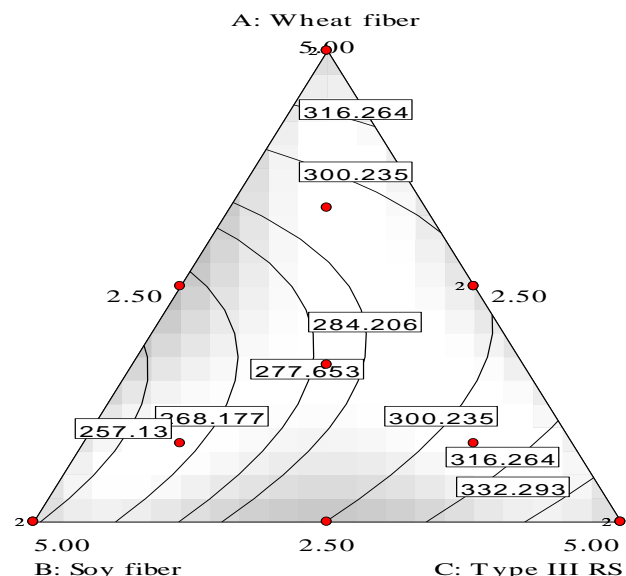

Tear force $\left(\begin{array}{ll}O & D\end{array}\right)$

Fig.1 (b)

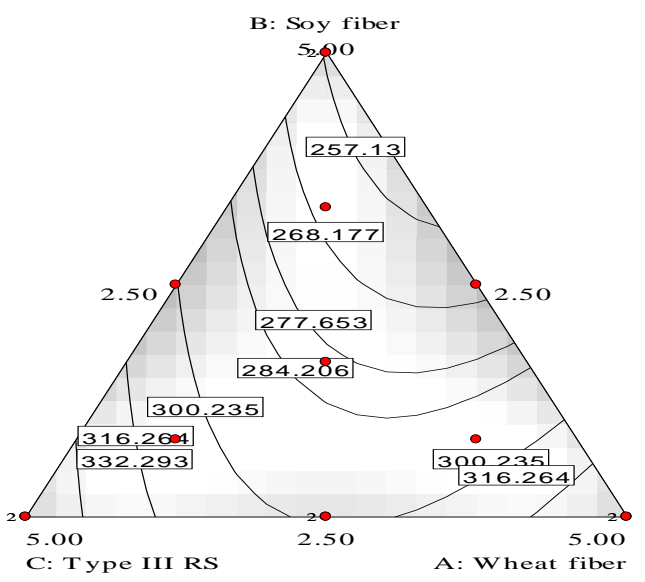

Tear force (O D)

\section{Fig.1 (c)}

Figure 1 Contour plot of chapatti tear force (0 Day); Fig. 1 (a) the effect of wheat fiber and soy fiber; Fig.1 (b) the effect of wheat fiber and type III RS Fig.1 (c) the effect of soy fiber and type III RS on tear force (0 Day). Other variables are held at zero level.

The contour plots are generally the graphical representations of the regression equation from which the values of tear force $(0,1,2$ day) and for different mixtures of variables respectively can be predicted. Each contour curve represents an infinite number of combinations of two least variables with the other maintained at zero level. The maximum predicted value is indicated by the surface confined in smallest ellipse in the contour diagram. Figures 1a-1c, shows the triangle contour plot for chapatti tear force (0 Day). Figure 1a shows interaction between wheat fiber and soy fiber. As soy fiber content in the mixture increased the softness of chapatti was also increased. The increased wheat fiber content also resulted in decreased softness of the chapatti while addition of type III RS resulted in increased hardness of the chapatti.
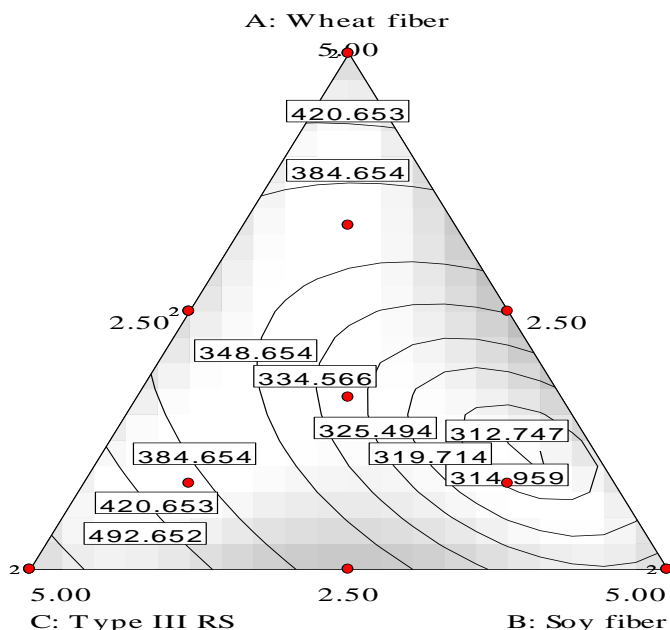

Tear force ( 1 D)

Fig. 2 (a)

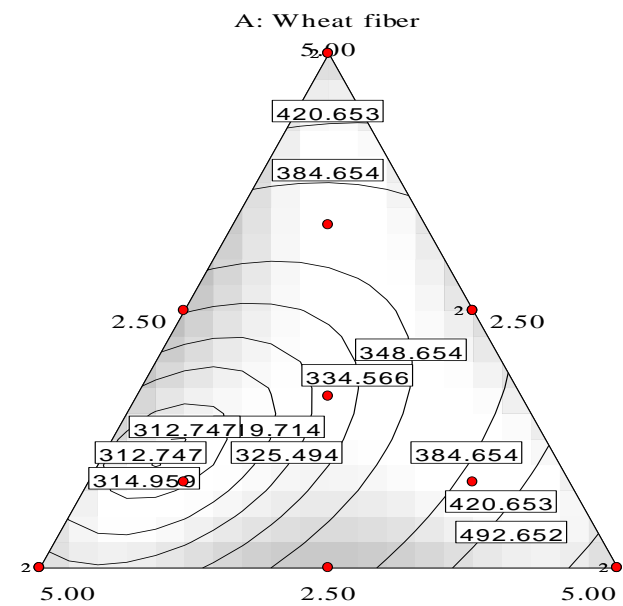

B: Soy fiber

C: Type I

Tear force $\left(\begin{array}{ll}1 & D\end{array}\right)$

Fig. 2(b)

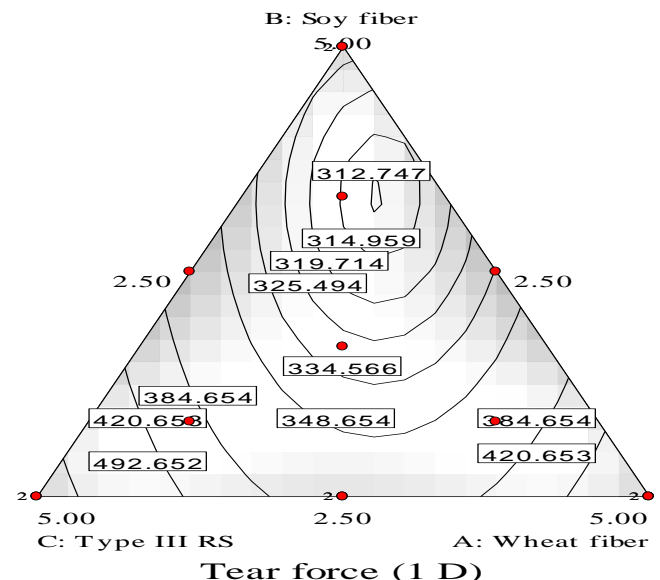

Fig.2 (c)

Figure 2 Contour plot of chapatti tear force (1 Day) Fig. 2 (a) the effect of wheat fiber and soy fiber; Fig.2 (b) the effect of wheat fiber and type III RS Fig.2 (c) the effect of soy fiber and type III RS on tear force (1 Day). Other variables are held at zero level. 
Figure 2a depicts "mound shaped" surface at the corner. The contour line indicates that chapatti tear force was dependent on soy fiber and wheat fiber content. Figure $2 \mathrm{~b}$ shows similar type of contour as Figure $2 \mathrm{a}$ and it can be seen that highest tear force values occurred at high soy fiber $(5.00 \%)$ addition and at low wheat fiber $(2.50 \%)$ addition. Figure $.2 \mathrm{c}$ shows similar contour as Figure $2 \mathrm{~b}$ for tear force values, whereas the response surface is more dependent on the soy fiber content.
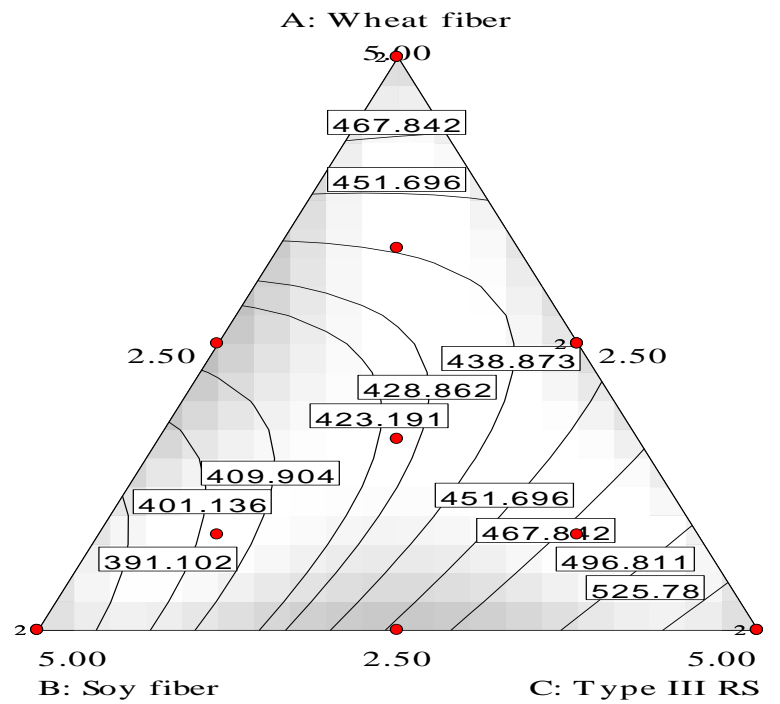

Tear force $(2 \mathrm{D})$

Fig. 3(a)

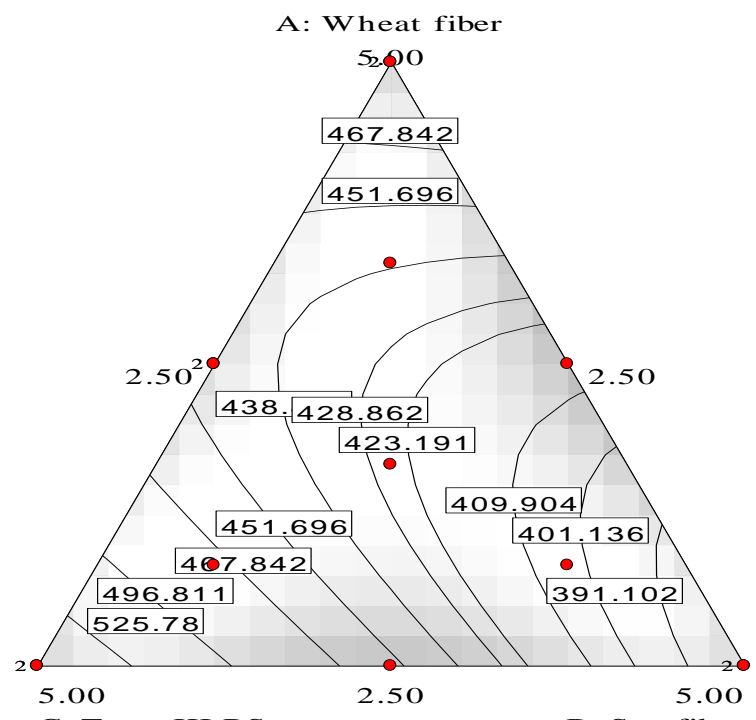
C: Type III RS
B: Soy fiber

Tear force $(2 \mathrm{D})$

Fig. 3 (b)

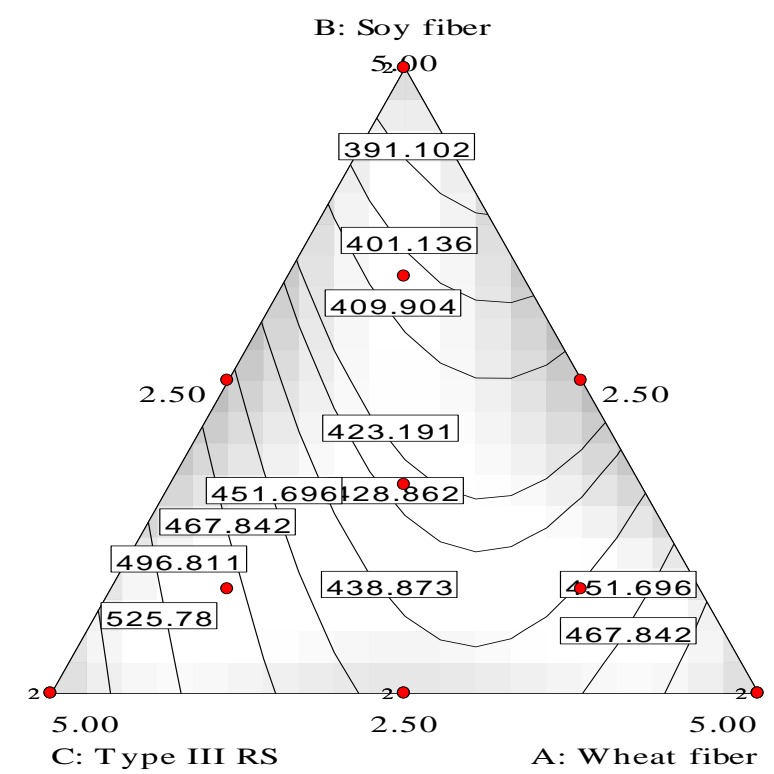

Tear force (2 D)

Fig. 3 ( c)

Figure 3 Contour plot of chapatti tear force (2 Day) Fig. 3 (a) the effect of whea fiber and soy fiber; Fig.3 (b) the effect of wheat fiber and type III RS Fig.3 (c) the effect of soy fiber and type III RS on tear force (2 Day). Other variables are held at zero level.

Figures 3a- 3c show ternary response \& contour plot of calculated tear force $(2$ day). Figure 3a illustrates contour plot of chapatti tear force after two days storage from the interaction between wheat fiber and soy fiber while keeping the other at 0 levels. A linear increase in chapatti hardness was observed when soy fiber was decreased from $5 \%$ to $2.50 \%$. When wheat fiber was increased from $2.5 \%$ to $4.17 \%$ a linear decrease in the hardness was observed. Figure $3 \mathrm{~b}$ depicts the effect of wheat fiber and type III RS on tear force (2 Day). Wheat fiber at $2.92 \%$ and soy fiber at $4.17 \%$ resulted in retention of softness of chapatti. Similar pattern was observed with respective to Figure $3 \mathrm{c}$.

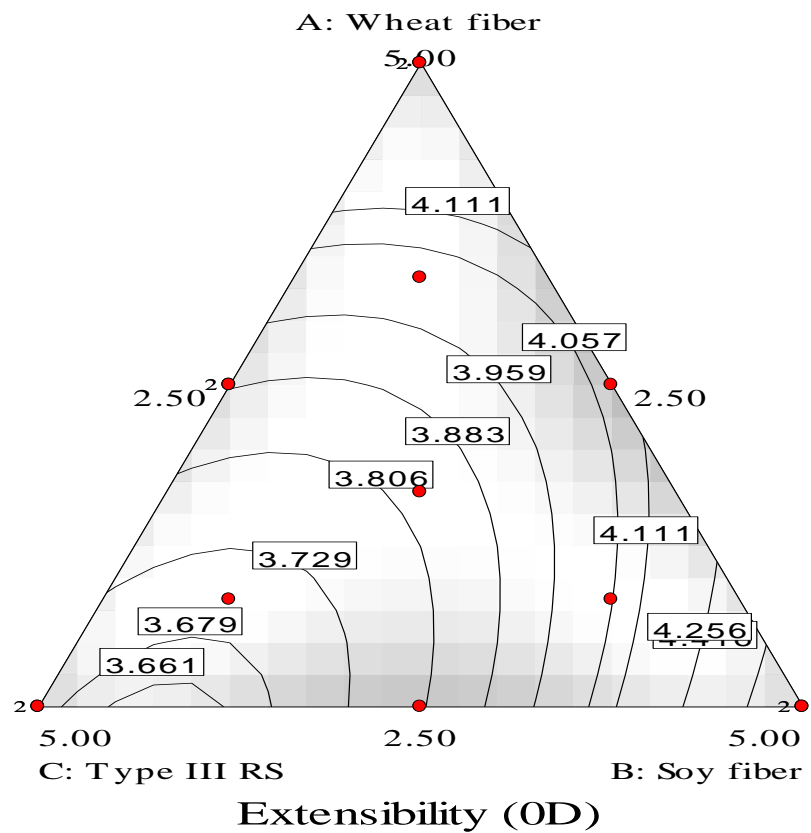

Fig 4 (a) 


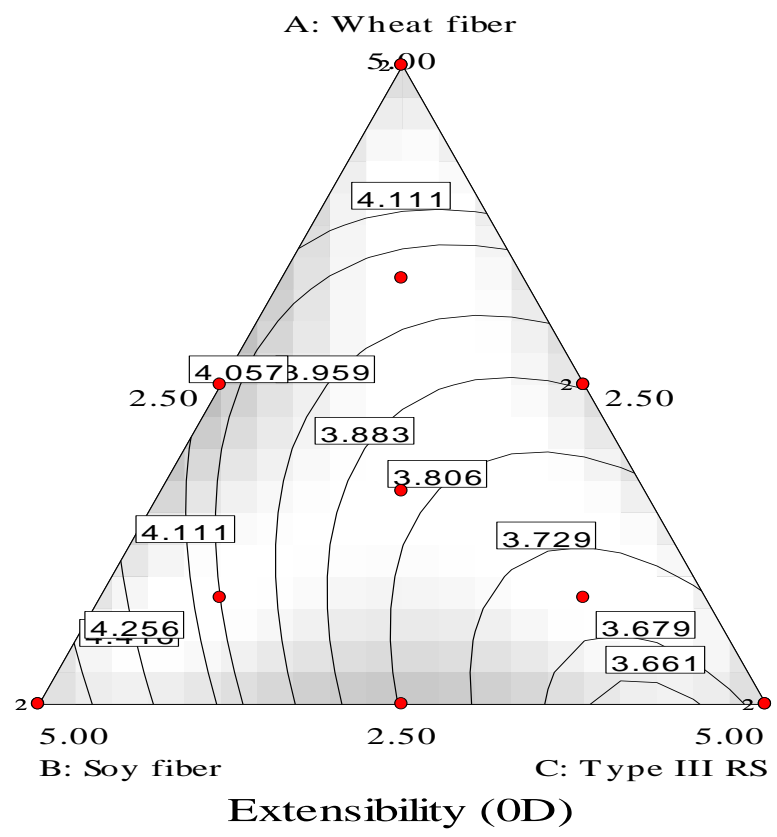

Fig 4 ( b)

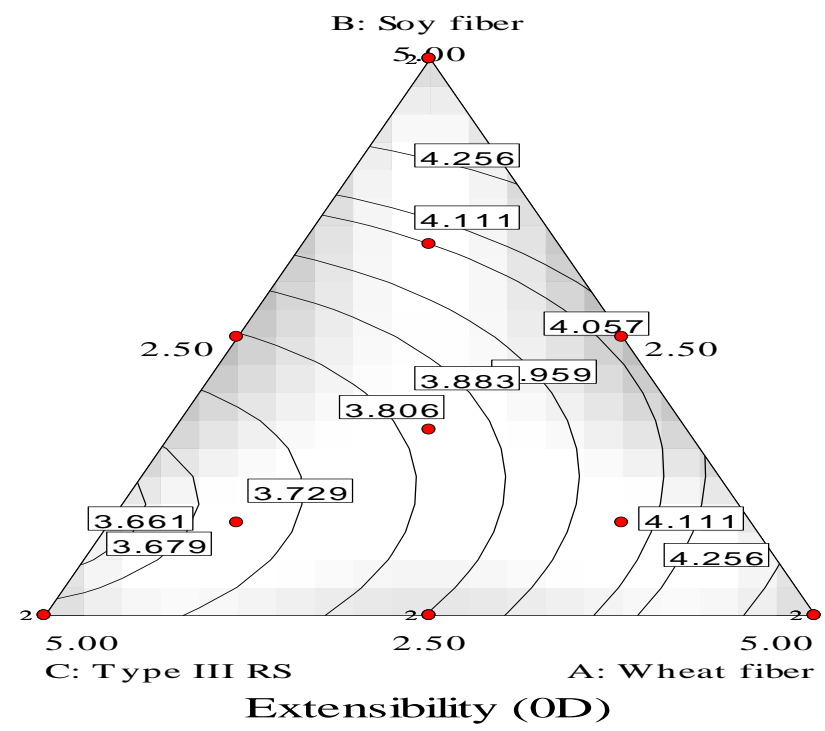

Fig 4 (c)

Figure 4 Contour plot of chapatti extensibility (0 Day); Fig. 4 (a) the effect of wheat fiber and soy fiber; Fig.4 (b) the effect of wheat fiber and type III RS Fig.4 (c) the effect of soy fiber and type III RS on extensibility (0 Day). Other variables are held at zero level.

Figure 4a represents ternary response $\&$ contour plot of chapatti extensibility ( 0 day) with the interaction of the effect of wheat fiber and soy fiber. Extensibility of the chapatti was increased as type III RS addition was increased; this was due to the overall increased hardness of chapatti due to the addition of type III RS which contained $97 \%$ amylose and amylose has been reported as main reason for staling in starch containing products. As can be seen from contour plot of chapatti extensibility (0 Day); the effect of wheat fiber and soy fiber on extensibility chapatti (Figure 4a) with the addition of soy fiber and wheat fiber extensibility was increased and, with the addition of type III RS; extensibility was decreased (Figure $4 \mathrm{~b}$ ). Figure $4 \mathrm{bc}$ showed similar trend.

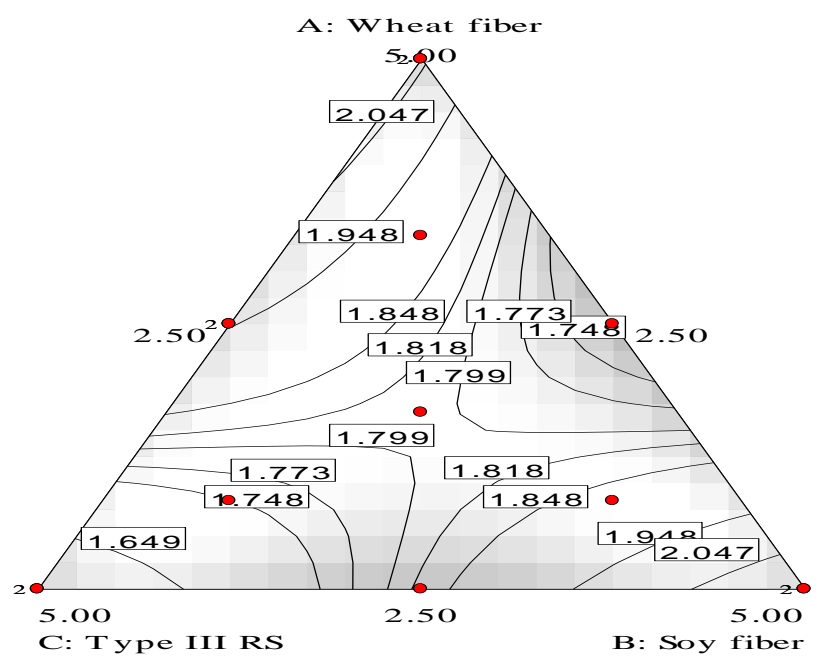

Extensibility ( 1 D)

Fig. 5a

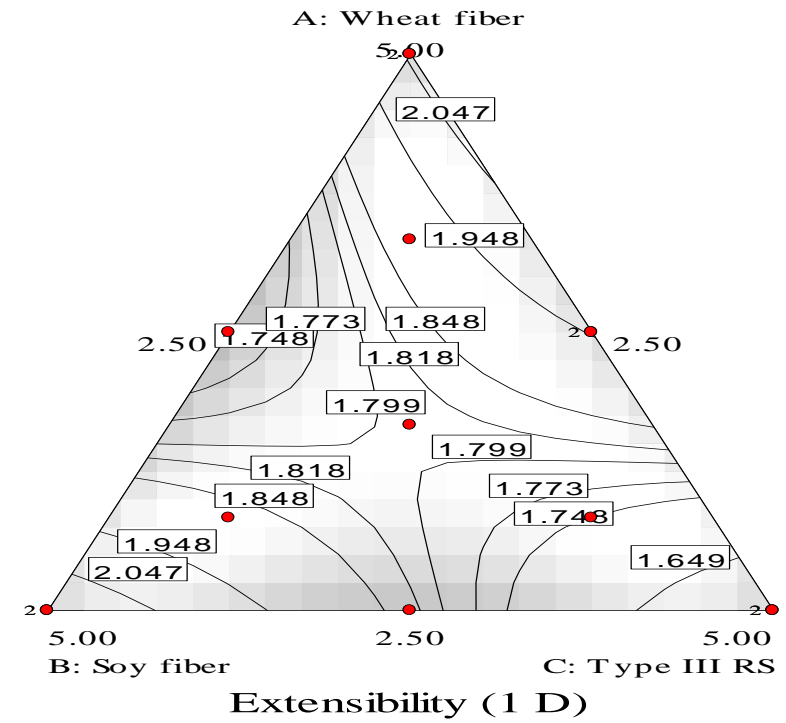

Fig. 5b

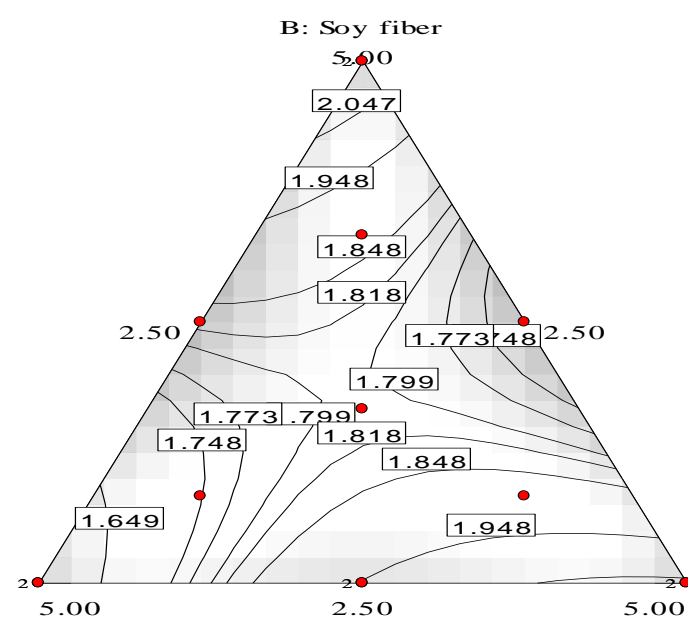

C: Type III RS A: Wheat fiber

Extensibility ( 1 D)

Fig. 5c

Figure 5 Contour plot of chapatti extensibility (1 Day); Fig. 5(a) the effect of wheat fiber and soy fiber; Fig.5 (b) the effect of wheat fiber and type III RS Fig. 5 (c) the effect of soy fiber and type III RS on extensibility (1 Day). Other variables are held at zero level 
In figures 5a- 5c show that one asymmetric saddling at the center of contour plot, indicating a rather complex relationship between the independent and dependant variable. Saddle point is indicated as the absence of a unique maximum or minimum. Higher level of soy fiber added in chapatti resulted in retention of extension values even after two days of storage, indicating soy fiber as an antistaling agent which prevented the loss in elasticity due to retrogradation.

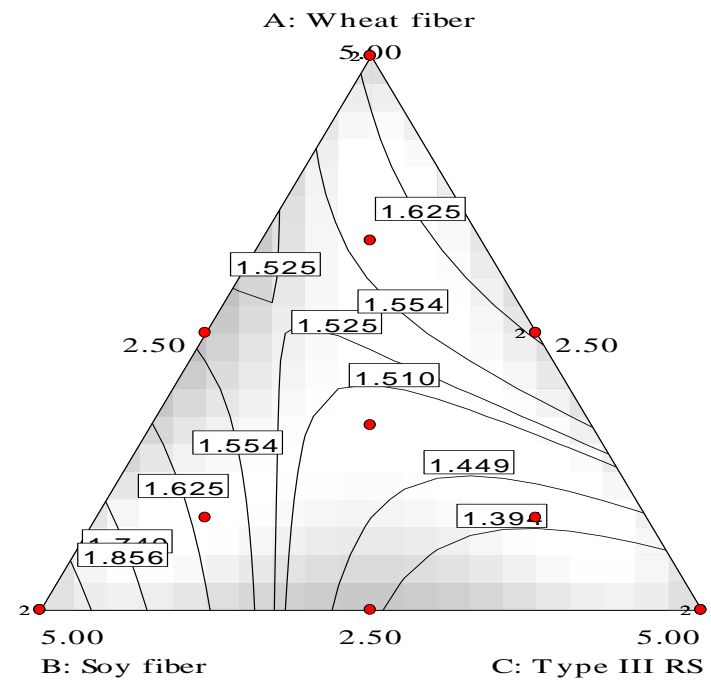

Extensibility (2 D)

Fig. 6a

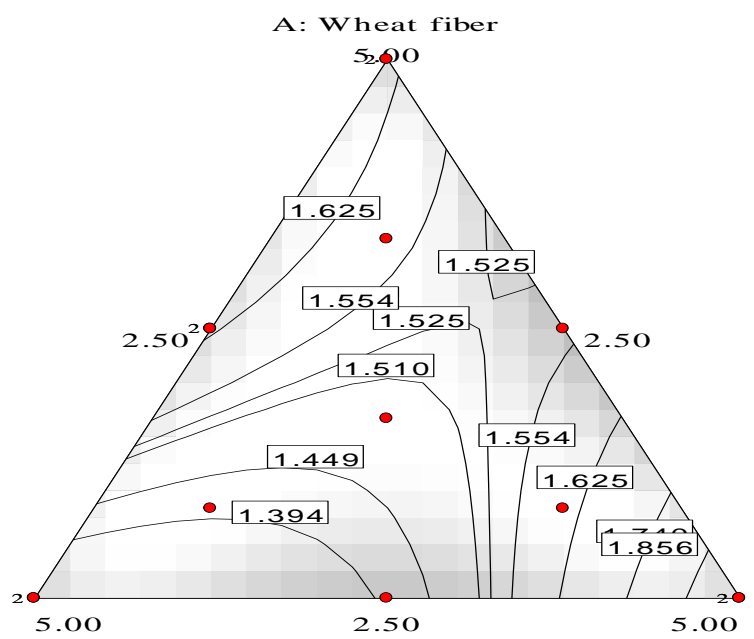

C: Type III RS B: Soy fiber

Extensibility (2 D)

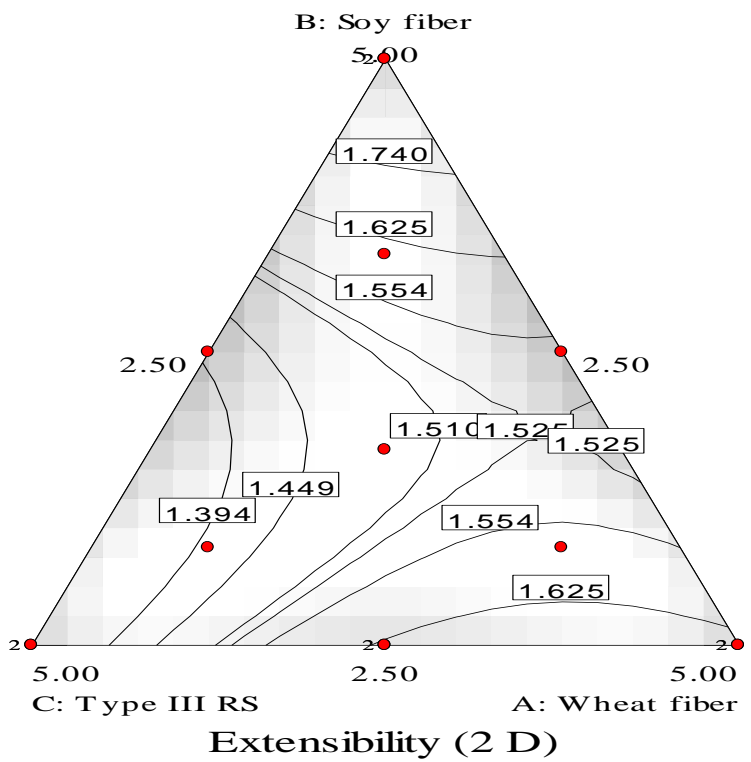

Fig. 6c

Figure 6 Contour plot of chapatti extensibility (2 Day); Fig. 6(a) the effect of wheat fiber and soy fiber; Fig.6 (b) the effect of wheat fiber and type III RS Fig. 6(c) the effect of soy fiber and type III RS on extensibility (2 Day). Other variables are held at zero leve.

Figures $6 \mathrm{a}-6 \mathrm{c}$ depict the complex relationship between the independent and dependent variable. The decreased extensibility in chapatti indicated loss in freshness of chapatti (Ghodke et al, 2009) on 2 day of storage. Pomeranz et al (1977) observed the deleterious effects of fiber addition on bread dough structure and suggested that it could be due to the dilution of the gluten network, which in turn impairs gas retention rather than gas production. This was detected in a microscopic examination in which a major difference between the crumb structure of control and fiber containing breads was detected (Pomeranz et $\boldsymbol{a l}$. 1977). The crumb structure of wheat breads was composed of thin sheets and filaments which were essentially absent in fiber -enriched breads. According to Gan et al. (1992) the bran materials in expanded dough appear to disrupt the starch gluten matrix and also restrict and force gas cells to expand in a particular dimension. This greatly distorts the gas cell structure and may contribute to the resultant crumb morphology which is an important element of crumb texture. Supplementation of baked products with dietary fiber requires changes in processing techniques for production of baked goods to achieve good consumer quality.

\section{CONCLUSION}

From present study it can be observed that addition of wheat, soy and type III RS fibers to whole wheat flour affected the rheological characteristics of the dough in various ways. The addition of these fibers in mixture decreased the dough stickiness and improved dough strength. This is beneficial from the industry poin of view where the energy required is reduced due to reduced stickiness. Dough containing wheat fiber $(2.5 \%)$, soy fiber $(5.0 \%)$ and type III RS $(2.5 \%)$ yielded highly acceptable chapattis in terms of textural properties. In the present study fibers, when added singly positively affected the quality of dough as well as chapatti; but when used in combination further improved the textural properties of chapatti hence the acceptability. These studies have demonstrated the potential for developing fiber -rich chapatti in order to increase the dietary fiber intake.

\section{ACKNOWLEDGMENTS}

Authors thank University Grant Commission, Government of India for their financial support for carrying out this work

\section{REFERENCES}

Abdul, H.A., Siew, L.Y. 2000. Functional properties of dietary fiber prepared from defatted rice bran. Food Chemistry, 68, 15-19. http://dx.doi.org/10.1016/s0308-8146(99)00145-4

Ames, N., Sopiwnyk, E.J., Therrien, M. 2003. Method of preparing tortillas from waxy barley cultivars. Patent No. US6635298B2.

Ang, J.F. 1993. Reduction of fat in fried batter coatings with powdered cellulose. Journal of American Oil Chemists Society, 70, 619-622. http://dx.doi.org/10.1007/bf02545330

Armero, E., Collar, C.1997. Texture properties of formulated wheat doughs 
relationship with dough and bread technological quality. Z Lebens Unte Forsch A. 204, 136-145. http://dx.doi.org/10.1007/s002170050050

Bollinger, H. 2000. Functional food: second generation dietary fiber. International Food Marketing and Technology, 14 (2), 6-8.

Box, G.E.P., Wilson, K.B. 1951. On the experimental attainment of optimum conditions. Journal of the Royal Statistical Society, 13, 1-38. http://dx.doi.org/10.1007/978-1-4612-4380-9 23

Chen, H., Rubenthhaler, G.L., Leung, H.K., Baranowski, J.D. 1988.

Chemical, physical and baking properties of apple fiber compared with wheat and oat bran. Cereal Chemistry, 65, 244-247.

Chen, W.Z., Hoseney, R.C. 1995. Development of an Objective Method for Dough Stickiness. Lebensmittel Wissenschaft und Technologie, 28,467-473. http://dx.doi.org/10.1006/fstl.1995.0079

Cornell, J.A. 2000. Developing mixture models, are we done. Journal of Statistical Computation and Simulation, 66: 2,127 - 144. http://dx.doi.org/10.1080/00949650008812018

Dhaliwal, A.S., Mac Ritchie, F. 1990. Contributions of protein fractions to dough handling properties of wheat-rye translocation cultivars. Journal of Cereal Science, 12, 113-122. http://dx.doi.org/10.1016/s0733-5210(09)80093-3

Dhaliwal, A.S., Mares, D.J., Marshall, D. R. 1990. Measurement of dough surface stickiness associated with the $1 \mathrm{~B} / 1 \mathrm{R}$ chromosome translocation in bread wheats. Journal of Cereal Science, 12, 165-175. http://dx.doi.org/10.1016/s07335210(09)80098-2

Dreese, P.C., Faubion, J.M., Hoseney, R.C. 1988. Dynamic rheologica properties of flour, gluten, and gluten- starch doughs. 2. Effect of various processing and ingredient changes. Cereal Chemistry, 65354 -359.

Gaines, C.S. 1982. Influence of dough absorption level and time on stickiness and consistency in sugar-snap cookie doughs. Cereal Chemistry, 59, 404- 407.

Gan, Z., Galliard, T., Ellis, P.R., Angold, R.E., Vaughan, J.G. (1992). Effect of the outer bran layers on the loaf volume of wheat bread. Journal of Cereal Science, 15, 151-163. http://dx.doi.org/10.1016/s0733-5210(09)80066-0

Ghodke, S.K. Ananthanarayan, L., Rodrigues, L. (2009). Use of response surface methodology to investigate the effects of milling conditions on damaged starch, dough stickiness and chapatti quality. Food Chemistry, 112, 1010-1015 http://dx.doi.org/10.1016/j.foodchem.2008.05.036

Guarda, A., Rosell, C.M., Benedito, C., Galotto, MJ.2004. Different hydrocolloids as bread improvers and antistaling agents. Food Hydrocolloid, 18 241-247. http://dx.doi.org/10.1016/s0268-005x(03)00080-8

Haseborg, E., Himmelstein, A. 1988, Quality problems with high-fiber breads solved by use of hemicellulase enzymes. Cereal Foods World, 33, 419-422.

Heddleson,S.S., Hamann, D.D., Lineback, P.R., Slade, L. 1994. Pressure-

sensitive adhesive properties of wheat flour dough and the influence of temperature, separation rate and moisture content. Cereal Chemistry, 71,564-570. Hlynka, I. 1970. Rheological properties of dough and their significance in the bread making process. Baker's Digest, 44, 40-46, 57.

Jeltema, M.A., Zabik, M.E., Thiel, L. J. 1983. Prediction of cookie quality from dietary fiber components. Cereal Chemistry, 60: 227-230.

Jones, R.W., Erlander, S.R. 1967. Interactions between wheat proteins and dextrans. Cereal Chemistry 44, 447-453.

Knuckles, B.E., Hudson, C.A., Chiu, M.M., Sayre, R.N. 1997. Effect of $\beta$-glucan barley fractions in high-fiber bread and pasta. Cereal Foods World.,42: 94-100. Mendonca, S., Grossmann, M.V.E., Verhe, R. 2000. Corn bran as a fiber source in expanded snacks. Lebensmittel Wissenschaft und Technologie, 33: 2-8, http://dx.doi.org/10.1006/fstl.1999.0601

Moore, D., Sanei, A., van Hecke, E., Bouvier, J.M. 1990. Effect of ingredients on physical structural properties of extrudates. Journal of Food Science, 55, 13831402. http://dx.doi.org/10.1111/j.1365-2621.1990.tb03942.x

Morrison, S.J., Marta, S.I., Ken, R.P., Jim, E.D. 2008. Evaluation of baking procedures for incorporation of barley roller milling fractions containing high levels of dietary fiber into bread. Journal of the Science of Food and Agriculture, 88, 558-568. http://dx.doi.org/10.1002/jsfa.3043

Myers, R.H., Montgomery, D.C. 1995. Response Surface Methodology. Wiley, New York. DOI: 10.1081/E-EBS2-120007631

Noguchi,G., Shinya, M., Tanaka, K., Yoneyama, T.1976. Correlation of dough stickiness with texturometer reading and with various quality parameters. Cereal Chemistry, 53, 72-77.

Piteira, M.F., Maia, J.M., Raymundoc, A., Sousa, I. 2006. Extensional flow behavior of natural fiber-filled dough and its relationship with structure and properties. Journal of Non-Newtonian Fluid Mechanics, 137, 72-80 http://dx.doi.org/10.1016/j.jnnfm.2006.03.008

Pomeranz, Y., Shogren, M., Finney, K F., Bechtel, D.B. 1977. Fiber in bread making-effects on functional properties. Cereal Chemistry, 54, 25-41.

Ram, B.P., Nigam, S.N. 1983. Texturometer as a tool for studying varietal differences in wheat flour doughs and gluten proteins. Journal of Texture Studies, 14, 245-249. http://dx.doi.org/10.1111/j.1745-4603.1983.tb00347.x

Ranhotra, G. 1993. Applications of Lecithin in Bakery Foods. Lecithin Research Department Bulletin. 5, 12.

Ranhotra, G.S., Gelroth, J.A., Astroth, K., Posner, E.S. 1990. Distribution of total and soluble fiber in various millstreams of wheat. Journal of Food Science, 55, 1349-1351. http://dx.doi.org/10.1111/j.1365-2621.1990.tb03933.x
Sánchez-Alonso, I., Haji-Maleki, Javier Borderias, A. 2007. Wheat fiber as a functional ingredient in restructured fish products. Food Chemistry, 100, 10371043. http://dx.doi.org/10.1016/j.foodchem.2005.09.090

Seibel, W, (1983). Anreiching von Brot und Kleingeba. ck mit verschiedenen Ballastoten. Getreide, Mehl und Brot, 37, 377-379.

Shaikh, I.M., Ghodke, S.K., Ananthanarayan, L. 2007. Staling of chapatti (Indian unleavened flat bread). Food Chemistry 101, 113-119. http://dx.doi.org/10.1016/j.foodchem.2006.01.015

Shaikh, I.M., Ghodke, S.K., Ananthanarayan, L. 2008. Inhibition of Staling In Chapatti (Indian Unleavened Flat Bread). Journal of Food Processing and Preservation, 32,378-403. http://dx.doi.org/10.1111/j.1745-4549.2008.00185.x

Sidhu, J.S., Al-Hooti, S.N., Al-Saqer, J.M. 1999. Effect of adding wheat bran and germ fractions on the chemical composition of high-fiber toast bread. Food Chemistry, 67, 365-371. http://dx.doi.org/10.1016/s0308-8146(99)00123-5

Sudha, M.L., Baskaran, V., Leelavathi, K. 2007. Apple pomace as a source of dietary fiber and polyphenols and its effect on the rheological characteristics and $\begin{array}{llll}\text { cake making. Food } \quad \text { Chemistry, } & \text { 686-692. }\end{array}$ http://dx.doi.org/10.1016/j.foodchem.2006.12.016

Thebaudin, J.Y., Lefebre, A.C., Harrington, M., Burgeois, C.M. 1997. Dietary fibers: nutritional and technological interest. Trends in Food Science and Technology, 8 41-48. http://dx.doi.org/10.1016/s0924-2244(97)01007-8

Waring, J. 1998. Resistant starch in food applications, Bulletin, National Starch and Chemical Company.

Yanniotis, S., Petraki, A., Soumpasi, E. 2007. Effect of pectin and wheat fibers on quality attributes of extruded cornstarch. Journal of Food Engineering, 80, 594-599. http://dx.doi.org/10.1016/j.jfoodeng.2006.06.018 